\title{
A Pilot Study of the effects of Yoga Prana Vidya (YPV) protocols on social behaviour, cognitive abilities and IQ of mentally challenged children
}

\author{
Khatri R. ${ }^{1}$, Bembalkar S. ${ }^{2}$, Nanduri V. ${ }^{3 *}$ \\ DOI: https://doi.org/10.17511/ijpr.2021.i01.02
}

${ }^{1}$ Rajkumari Khatri, Senior ENT \& Head Neck Oncologist, YPV Trainer \& Healer, Indore, Madhya Pradesh, India.

2 Shilpa Bembalkar, Technical officer(B), ICMR National AIDS Research Institute, Pune, Maharastra, India.

3* V S Nanduri, Consultant - Research \& Publications, Yoga Prana Vidya ashram, Sri Ramana Trust, Thally, Tamilnadu, India.

Introduction: Mental retardation is a neurodevelopmental disability of children. In this pilot study the authors have applied Yoga Prana Vidya system protocols for a pilot sample of mentally retarded children to study the effects and improvements in their being. Objectives: To assess (1) improvements of social behaviour, cognitive abilities and IQ, (2) reduction in morbidity, and (3) the effects on the frequency and duration of epilepsy attacks and seizures. Design: This is a longitudinal study of 2 years duration mixed methods design using YPV intervention on a selected pilot-scale sample, collecting data on qualitative observations of social behaviour, and measurements of cognitive abilities and IQ pre and post-test for quantitative analysis. Results: Statistical analysis of quantitative data revealed a significant increase in concentration, concept test, memory test, understanding, and social behavior. some increase in IQ and drawing test was present, however not found statistically significant. There was a reduction in the frequency and duration of epileptic attacks in epileptic children. Conclusion: This study has demonstrated that the YPV modality of complementary therapy has great utility and scope in improving the social behaviour, cognitive abilities and IQ of mentally challenged children. It is recommended that the earlier the intervention is conducted for the challenged children the better and sooner will be the better quality of life for them in terms of improved mental, emotional, and physical health. Further research with longitudinal fullscale studies is recommended to investigate this phenomenon widely.

Keywords: Mentally retarded children, epilepsy, yoga, meditation, Energy Healing, Complementary and Alternative Therapy

Corresponding Author

V S Nanduri, Consultant - Research \& Publications, Yoga Prana Vidya ashram, Sri Ramana Trust, Thally, Tamilnadu, India.

Email: vsnanduri@yahoo.com

\section{How to Cite this Article}

Khatri R, Bembalkar S, Nanduri VS. Running Head: A pilot study on Yoga Prana Vidya for improvements in mentally Challenged children. Pediatric Rev Int J Pediatr Res. 2021;8(1):07-15.

Available From

https://pediatrics.medresearch.in/index.php/ijpr/arti cle/view/653
To Browse

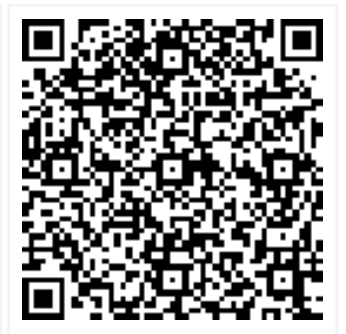

Manuscript Received 2021-01-26

Conflict of Interest No (c) 2021 by Rajkumari Khatri, Shilpa Bembalkar, V S Nanduri and Published by Siddharth Health Research and Social Welfare
Society. This is an Open Access article licensed under a Creative Commons Attribution 4.0 International License https://creativecommons.org/licenses/by/4.0/ unported [CC BY 4.0].

Accepted 2021-02-15 2021-02-06 unding (1/ 


\section{Introduction}

The status of the welfare of persons with mental disability in India, concerning the provision of education and employment opportunities for persons with mental retardation received its formal recognition after the Persons with Disabilities Act (PWD), 1995 came into existence, which was updated by the Rights of PWD Act, 2016 (RPWD Act, 2016) [1].

This has introduced the term "intellectual disability" in the place of "mental retardation." The principles of the enactment are: respect for inherent dignity, individual autonomy including the freedom to make one's own choices, and independence of persons. These principles reflect a new perspective of thinking about disability as a human rights issue than social welfare.

Mental retardation is a developmental disorder of considerable limitations in a person's intellectual functioning (reasoning, learning, problem-solving) and adaptive behaviors (a range of everyday selfcare, socializing and communication skills). It is widely referred to as "intellectual disability (ID)" and "intellectual developmental disorders (IDDs)." India being a signatory to the World Health Organization (WHO), the term "mental retardation" is still used in clinical practice, and both the terms, intellectual disability and mental retardation, are widely in use [2].

ID is generally connected with various medical comorbidities at various degrees of both neurological and nonneurological. Some comorbidities arise as a consequence of ID. The ICD-10 document (WHO) [3] provides the following levels of IQ as a guide, not to be applied rigidly, because of cross-cultural validity and these categories are arbitrary divisions of Mental Retardation:

\begin{tabular}{|l|l|l|l|}
\hline 1. & Mild & IQ Scores $50-70$ & Prevalence of about $85 \%$ \\
\hline 2. & Moderate & IQ Scores $35-49$ & prevalence of $10 \%$ \\
\hline 3. & Severe & IQ Scores $20-34$ & prevalence of 3-4\% \\
\hline 4. & Profound & IQ Scores below 20 & \\
\hline
\end{tabular}

Normal IQ Score is $>90$. IQs between 80 and 120, with an IQ of 100 is considered average. To be diagnosed as having mental retardation, a person's IQ is to be below 70-75, i.e. significantly below average. Approximately $85 \%$ of the mentally retarded population is in the mildly retarded category.
Data obtained from various sources indicate that the prevalence rate of mental retardation is about 20 per 1000 general population, while the prevalence of developmental delays is about 30 per 1000 in the 14-year-old population. In rural areas, the incidence of mental retardation is $3.1 \%$ and in urban, it is $0.9 \%$. [4]

Literature shows that Yoga-based therapies have been applied to cases of mental retardation and related deficiencies to improve patients condition. Yoga is considered as a treatment for mental disorders, including mood disorders, psychological disorders, behavior and development disorders, drug addiction, mental retardation, pain management [5] [6] and also physical fitness, cardio-respiratory effects, motor skills/strength, irritable bowel syndrome, and birth outcomes following prenatal yoga [6].

The aims of yoga are the development of : (1) a strong and flexible body free of pain., (2) a balanced autonomic nervous system with all physiological systems, e.g., digestion, respiration, endocrine, functioning optimally, (3) a calm, clear, and tranquil mind. Besides, yoga practices are intended to facilitate self-transformation at every level of functioning, to improve the overall quality of life [7].

Yoga breathing (pranayama) requires a person to inhale deeply through the nose into the lungs. [8] Yoga and meditation practice is found for enhancing cognition and greater grey matter volume (GMV) in various brain areas. [9] [10] The physical exercises (asanas) may increase physical flexibility, coordination, and strength, while the breathing practices and meditation may calm and focus the mind to develop greater awareness and diminish anxiety, [11] and improvement in a positive mood, spiritual health, spiritual experiences, and tolerance to pain. [10] There is scientific evidence that yogic practices enhance mental health. [12]

A study of the effects of the integrated approach of yoga therapy (IAYT) for mentally retarded children found significant improvement in the moderately retarded test group compared to their initial performance, as well as in that of the control group. [13] This improvement in static motor performance can be attributed to better eye-hand co-ordination, improved fine motor control, concentration, and also an overall state of well-being and relaxation. [13] [14] Healing happens in a state of consciousness exactly opposite to the state of crises [15]. 
These studies suggest that considerable plasticity and scope for improvement in motor performance, cognitive abilities, is still present in Mentally challenged children. A study on the effect of yoga on epilepsy suggested that Yoga would be an attractive therapeutic option for epilepsy, may induce relaxation and stress reduction, and influence the electroencephalogram and the autonomic nervous system, thereby controlling seizures. [16] A study using the Transcendental Meditation technique reported improvements in a 26year old female patient on her verbal and social behavior and physiological functioning over three years while practising the technique.[17] Another study observed that the children who have difficulty in concentration, seem to be constantly in motion. [18] Some researchers have suggested that excess stress can be lowered in children through physical exercise which may, in turn, improve their performance on intellectual activity. However, no reliable conclusions can be drawn regarding the efficacy of yoga as a treatment for uncontrolled epilepsy. [19] Yoga therapy is mainly about using certain body postures to influence the body and mind to normalize emotional and mental disturbances resulting in more even thoughts and feelings enabling relief from certain diseases and disorders. There is a general lack of research studies exploring the effect of yoga on cognitive development in mentally retarded children. With this in view, the investigators have undertaken this study using Yoga Prana Vidya (YPV) intervention to find its effects on social behaviour, cognitive development, and IQ of mentally retarded children.

Yoga Prana Vidya (YPV) System: To do Yoga postures, known as yoga asanas, a person's body has to be in fit condition and flexible. In contrast to therapies using Yoga postures, a relatively easier and safer way is to work on the energy body which encapsulates the physical body. Figure 1 below shows a picture of the energy body of a normally healthy person alongside a sick person's energy body, for comparison.

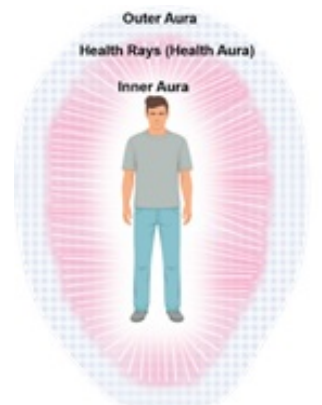

\section{Fig-1: Comparison of energy bodies of normal healthy and sick persons}

This energy healing system is known as the Yoga Prana Vidya system, which is holistic and integrated, uses no -drug no-touch protocols, energy healing working on Chakras and energy body, The condition of the Chakras and energy body can be diagnosed with either hand scanning by a trained and skilled healer, or mapped using a GDV(Gas Discharge Visualisation) camera specially designed and established in this field. The GDV camera screening process is relatively cost-effective, and can be practised with some training.

YPV system of holistic healing science is based on ancient practices of Holy Masters, and is known to be effective in treating physical and psychological ailments. [20] In the usual way of healing both healer and client (patient)are in the same room which is called proximal healing. The other way is when the healer is far from the client (patient), at a distance even extending to several hundred or thousands of Kilometers, and the healing energy is effectively delivered [21], which process is known as distant or distal healing.

One of the authors is the principal investigator of this study who is an experienced Yoga Prana Vidya (YPV) healer, and had been rendering healing service to mentally retarded children of the special school to improve their quality of life. The teachers of the school, where the author rendered services earlier, noticed the changes in behavior, concentration, memory and reduction in the frequency and duration of the epileptic attack. Encouraged by this background the School Principal requested the principal investigator to conduct this pilot study and document the outcomes.

\section{Material \& Methods}

Research Design: This is a prospective interventional pilot study of 2 years duration with a mixed-methods design (both quantitative and qualitative) of Yoga Prana Vidya (YPV) application for the Mentally challenged children of a special school for children. Ethics clearance from IEC (Institutional Ethics committee) had been obtained before commencing fieldwork.

\section{YPV intervention for the study}

The following YPV technique-modules were applied to all the subjects (participants of the study): 
01. SuperBrain Asana, 2.Physical exercise, 3. Breathing exercise, 4.Planetary peace Meditation, 5.Forgiveness sadhana, and 6. YPV healing.

Initially the sample children practised under the guidance of a trained YPV practitioner, and later on, practised under the guidance of the school teacher by using the YPV sadhana app on mobile downloaded from Google play store. Throughout the study, Planetary peace meditation was done once a week under the guidance of a trained YPV practitioner. Distant YPV Healing was done initially daily for 3 months, followed by three times a week for 9 months, and once a week for 12 months.

\section{The subjects (participants) of the Study}

Sample selection criteria: Mentally retarded (MR) Children of any age and gender in the selected school who are willing to participate in the study are considered for inclusion. Accordingly, MR children were recruited for this pilot study from the Government school of mentally challenged children in a city in India after obtaining informed consent from the Dean of the School. Exclusion criteria consisted of a profound category of MR children, MR children with other severe illnesses, MR children not willing to participate in the study. An exception was made to include a 30 years old inmate of this school in this pilot study group.

Sample Size: 28 children were meeting the criteria, but 7 were not in a condition to follow the YPV instructions, and not taken for the study. The final sample selected was 21 . Of these 21 inmates selected, there were 16 males and 5 females, and most of them were in the age range of 12-18 years except for 2 subjects, one of which was 8 years and the other was 30 years.

\section{Data Collection}

Quantitative data collection tool: The participant sample was subjected to examination by a clinical
Psychologist using the revised version of the Vineland Social Maturity Scale (VSMS) which is currently the most widely used scale for the assessment of mental retardation of children.

Qualitative data collection tool: The investigator used a structured questionnaire to collect data from the school teachers of the children through interviews at the beginning and at the end of each year to assess the improvement in behavior, and cognitive abilities of the sample. The questionnaire included the following 10 factors of observation:

Type (a) factors; As feedback from teacher assessment, and observation of kid:

01. Concentration, 2. Understanding, 3. Drawing skill, 4. Psychological Behavior \& restlessness, Social behavior

Type (b) factors assessed by the interviewer while observing the kid in the teacher's presence:

06. Memory, 7.Shape recognition, 8. Colour recognition, 9.Concept, 10.Motor skills

Data Analysis: The random-effects model is used to statistically analyse data and assess the performance of children in various test scores over time. The analysis was performed in $\mathrm{R}$ which is a popular free software environment for statistical computing and graphics. $\mathrm{R}$ compiles and runs on $\mathrm{a}$ wide variety of platforms including Windows. The results of the study group of children thus obtained were compiled and compared before and after each year of completion.

\section{Results}

Quantitative analysis: The pre and postintervention data collected from the pilot study group were statistically analyzed using the $R$ programme to compare for changes. Table 1 below shows the year-wise distribution of various test scores performed on the participants in the study.

Table 1: $(\mathbf{N}=21)$ : Statistical outcomes of parameters assessed

\begin{tabular}{|c|c|c|c|c|}
\hline Parameter & $2018(N=21)$ & $2019(N=21)$ & $2020(N=21)$ & Coefficient ( $95 \% \mathrm{CI})$ \\
\hline \multicolumn{5}{|l|}{ IQ } \\
\hline Mean (SD) & $41.8(8.53)$ & $45.8(13.9)$ & $43.4(15.0)$ & \\
\hline Median [Min, Max] & $40.0[22.0,56.0]$ & $51.0[20.0,69.0]$ & $50.0[20.0,69.0]$ & $0.50(-1.51,3.08)$ \\
\hline \multicolumn{5}{|l|}{ Concentration } \\
\hline Mean (SD) & $21.4(23.3)$ & $43.3(26.9)$ & $67.9(35.0)$ & \\
\hline Median [Min, Max] & $20.0[0,80.0]$ & $50.0[0,90.0]$ & $80.0[0,100]$ & $23.21(16.98)$ \\
\hline \multicolumn{5}{|l|}{ Concept test } \\
\hline Mean (SD) & $25.7(23.4)$ & $39.9(23.5)$ & 62.4 (31.9) & \\
\hline
\end{tabular}


Khatri R. et al: A Pilot Study of the effects of Yoga Prana

\begin{tabular}{|c|c|c|c|c|}
\hline Median [Min, Max] & $30.0[0,60.0]$ & $40.0[0,80.0]$ & $70.0[0,100]$ & $18.33(13.51,23.26)$ \\
\hline \multicolumn{5}{|l|}{ Memory test } \\
\hline Mean (SD) & $2.19(2.16)$ & $4.52(3.30)$ & $5.24(3.28)$ & \\
\hline Median [Min, Max] & $2.00[0,9.00]$ & $5.00[0,10.0]$ & $6.00[0,10.0]$ & $1.52(0.80,2.24)$ \\
\hline \multicolumn{5}{|l|}{ Understanding } \\
\hline Mean (SD) & $27.9(14.4)$ & $38.1(25.0)$ & 68.6 (29.7) & \\
\hline Median [Min, Max] & $20.0[5.00,60.0]$ & $30.0[10.0,90.0]$ & $80.0[10.0,100]$ & $20.35(15.46,25.53)$ \\
\hline \multicolumn{5}{|l|}{ Drawing test } \\
\hline Mean (SD) & $1.38(2.71)$ & $3.24(3.27)$ & $3.81(3.79)$ & \\
\hline Median [Min, Max] & $0[0,8.00]$ & $3.00[0,10.0]$ & $4.00[0,10.0]$ & $1.2(0.69,1.73)$ \\
\hline \multicolumn{5}{|l|}{ Social behavior } \\
\hline Mean (SD) & $7.00(2.90)$ & $7.90(2.83)$ & $8.14(2.33)$ & \\
\hline Median [Min, Max] & $9.00[0,10.0]$ & $9.00[0,10.0]$ & $9.00[3.00,10.0]$ & $0.57(0.25,0.88)$ \\
\hline \multicolumn{5}{|l|}{ Colour performance } \\
\hline No & $0.810(1.69)$ & $1.57(2.80)$ & $3.00(3.36)$ & $1.09(0.71,1.47)$ \\
\hline Yes & $0[0,6.00]$ & $0[0,10.0]$ & $2.00[0,10.0]$ & \\
\hline \multicolumn{5}{|l|}{ Shape Performance } \\
\hline No & $10.0(0)$ & $7.90(4.02)$ & $9.43(1.91)$ & $9.68(-1.09,0.52)$ \\
\hline Yes & $10.0[10.0,10.0]$ & $10.0[0,10.0]$ & $10.0[2.00,10.0]$ & \\
\hline
\end{tabular}

In the matter of IQ as assessed by the clinical psychologist, it is observed from Table 1and Figure 2 that the increase in IQ was present, however not found statistically significant.

Fig 2:Graphical representation of IQ year wise

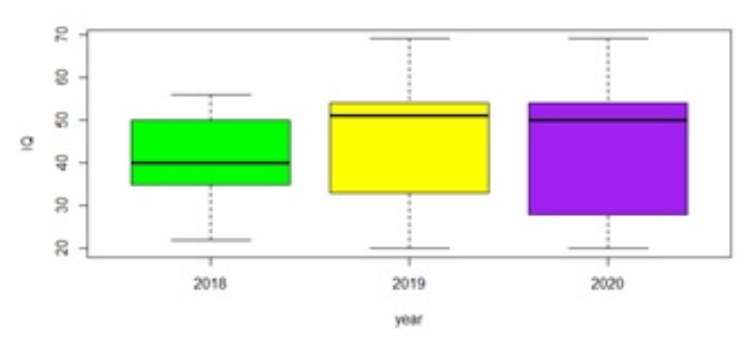

Table 2: IQ status of sample children pre \& post-study

\begin{tabular}{|l|l|l|l|}
\hline \multicolumn{1}{|c|}{ IQ Status } & \multicolumn{1}{|c|}{ Pre Study no. of children } & \multicolumn{1}{|c|}{ Post Study 2019 no. of children } & \multicolumn{1}{c|}{ Post Study 2020 no. of children } \\
\hline Mild (50-70) & $6(.57 \%)$ & $10(47.61 \%)$ & $12(57.14 \%)$ \\
\hline Moderate $(35-49)$ & $13(61.90 \%)$ & $5(23.8 \%)$ & $2(9.5 \%)$ \\
\hline Severe $(34-20)$ & $2(9.5 \%)$ & $6(28.5 \%)$ & $7(33.33 \%)$ \\
\hline
\end{tabular}

From Table 2 it is observed that at the end of the 2nd year of YPV intervention, the number of "moderately" retarded children decreased from 13 to 2 , and 6 of them improved to the "mild" category. However 5 of those categorised earlier as mild moved up to the "severe" category increasing the number from 2 to 7. The principal investigator and the clinical psychologist investigated these 7 cases in which there appeared a deterioration of the response or there was no response. It was found that 3 were non-responsive, and 2 were very aggressive and on sedative medication, and did not attend the practice classes.
The other 2 children were epileptic, and because of frequent epileptic attacks their mental activity was negatively influenced. However, on the other hand, as they went on practising in the intervention there was a reduction in the frequency and duration of the epileptic attacks. But due to damage to the brain by epilepsy there was not much improvement in their learning abilities, but some improvements in concentration, understanding and memor $y$ were observed.

Other factors: The beta coefficient shows the increase in concentration (fig 2), concept test (Fig 3), memory test (Fig 4), understanding (Fig 5), drawing test(Fig 6), social behaviour (Fig 7), and 
Colour recognition (Fig 8 ). The ability to recognize the shape was not significant.

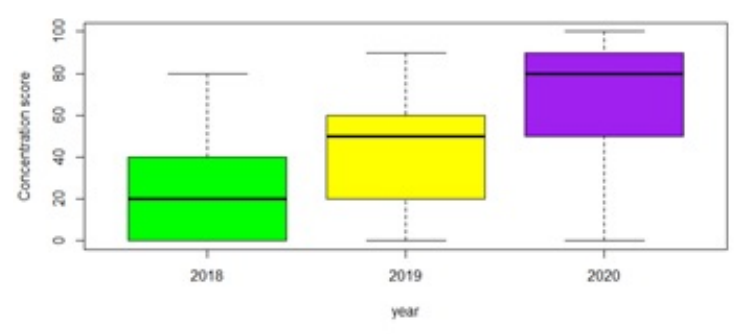

Fig3: Graphical representation of concentration year wise

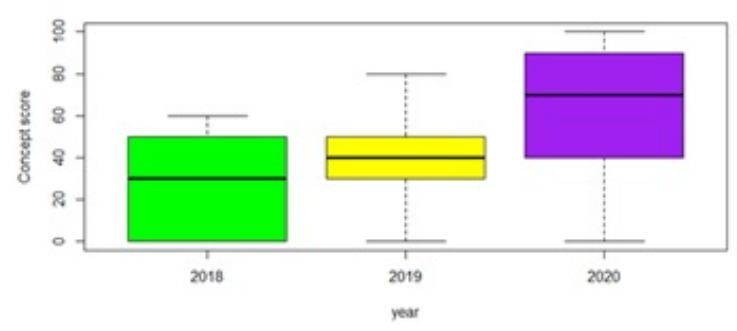

Fig4: Graphical representation of concept year wise

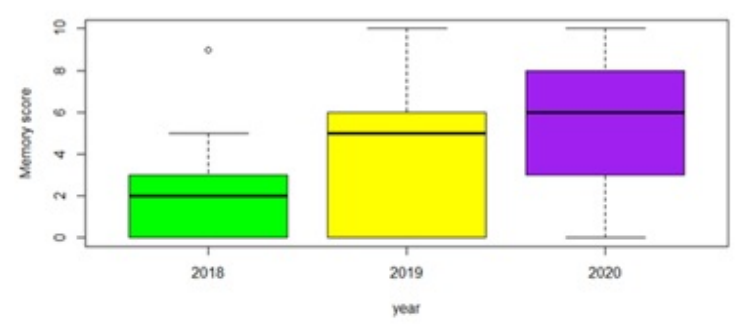

Fig5: Graphical representation of Memory, year-wise

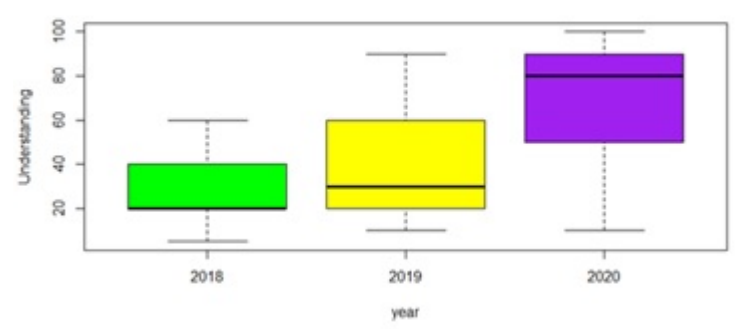

Fig6: Graphical representation of understanding year wise

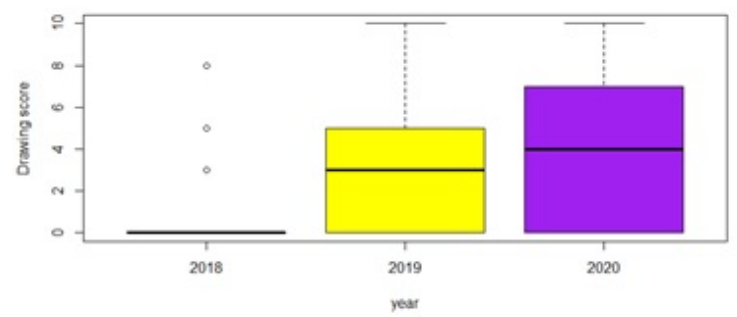

Fig 7: Graphical representation of drawing skill year wise

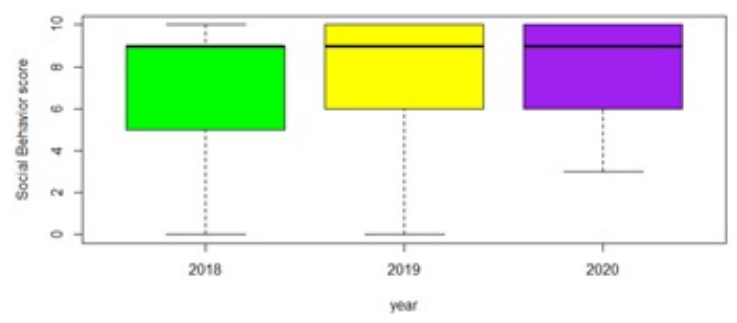

Fig 8: Graphical representation of social behavior year wise.

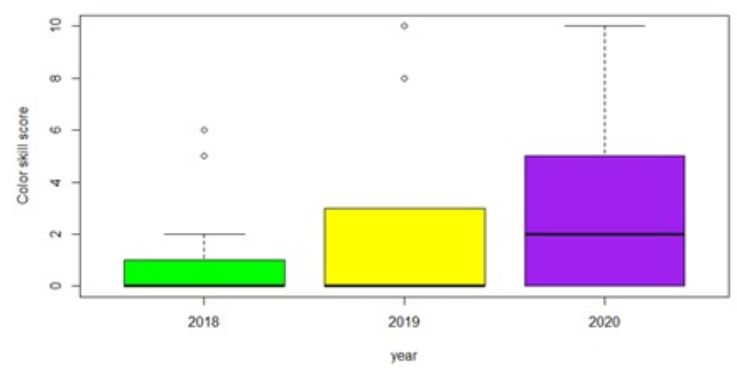

Fig 9: Graphical representation of the development of colour skill year wise.

Qualitative analysis: This study revealed the following changes in the quality of their life;

1. Motor skill: There was no change observed in their motor skills development.

2. language skills: Initially out of 21,15 had normal speech, 5(23\%) have no speech, 1 has slurred speech. next year $3(14.28 \%)$ had no speech, while other 3 had developed slurred speech and in last year, only $2(9.5 \%)$ have no speech, remaining all were able to communicate.

3. Restlessness: There was a noteworthy reduction in restlessness from $68.4 \%$ to $28.6 \%$ in the Ist year but slightly increased to $33.33 \%$ in the next year. 
4. Personal skills: As far as their skills of eating, dressing, cleanliness and toilet training are concerned, initially there were $76.20 \%$ of children who were able to take care of themselves, has increased to $95.3 \%$ after 1 year \& $100 \%$ after II nd year.

5. Behavior: Initially, all have abnormal behavior except 3 (14.28\%) children were aggressive in their behavior, biting and beating each other, tearing off clothes of self and others, abusive tendencies, stealing, telling lies, breaking the utensils like glass, thali, spoon, Katori ( small bowl), excessive shouting without any cause.

After 6 months from the start of the intervention, physical violence reduced almost to nil. After 1 year it was observed that they were doing group activity peacefully, helping each other in work, sharing food and other things amongst them, helping those who are weak and not able to do a certain activity, help each other in dressing.
Their anger, abusive tendencies, and aggressive behavior were dramatically reduced in frequency and severity, induced by provocation. At the end of the 1st year, the no of children with normal behavior is increased to $6(28.57 \%)$, and at the end of II nd year to $16(76.19 \%)$.

\section{Outcomes of YPV intervention on Epilepsy cases}

It has been observed that out of 21 subjects with MR, 8 (38.09\%) were on antiepileptic drugs, and out of this 8 , one subject had no history of epilepsy since 2010 but he was very violent in behavior++. while the other 7 subjects have active epilepsy, not responding to treatment. Referring to Tables $3 \& 4$, it is observed that there was a noticeable improvement in the frequency and duration of epilepsy. During the attack, there was no unconsciousness in any subject. no drowsiness in the postictal phase. The postictal recovery was remarkable.

Table 3: Pre-healing phase: Occurance of frequency and duration of an epileptic attack

\begin{tabular}{|l|l|l|l|l|}
\hline S.no & \multicolumn{1}{|c|}{ Frequency } & Duration & \multicolumn{1}{|c|}{ Remark } & \multicolumn{1}{|c|}{ Postictal } \\
\hline 1 & 2 -3/day & $5 \mathrm{~min}$ & Once in 15 days & no \\
\hline 2 & $3-5 /$ day & $10 \mathrm{~min}$ & Daily & drowsiness for $30 \mathrm{~min}$ \\
\hline 3 & $3-4$ times /day & $30 \mathrm{~min}$ & repeated after 15 days & drowsines for 2-3days \\
\hline 4 & no attack since 2010 & & violent behavior++ & no \\
\hline 5 & $3-4 /$ day & $20 \mathrm{~min}$ & repeated after $3 \mathrm{mths}$ & unconscious for $30 \mathrm{~min}$ \\
\hline 6 & $2-3 /$ day & $30 \mathrm{~min}$ & & Unconscious, drowsiness for 2-3days \\
\hline 7 & excessive crying \& shouting & 4 days & repeated after 15 days & \\
\hline 8 & Eating scalp hairs & daily & & \\
\hline
\end{tabular}

Table 4: Post-healing phase: Occurance of frequency and duration of an epileptic attack

\begin{tabular}{|c|c|c|c|c|}
\hline S.no. & Frequency & Duration & Remark & Postictal \\
\hline 1 & Epilepsy very rarely & $1-2 \min$ & Controlled & no \\
\hline 2 & once in a week & secs & no residual effect & No incontinence, drowsiness \\
\hline 3 & once in a day & secs & 15 days to $1 \mathrm{mth}$ & no drowsiness \\
\hline 4 & No & & no violence, only irritation & no \\
\hline 5 & 3-4 times in a year & $5 \mathrm{~min}$ & no unconsciousness, throwing limbs & no drowsiness \\
\hline 6 & once ina day, spasm only & mins & no unconsciousness, froth & no drowsiness \\
\hline 7 & no complaints & - & - & - \\
\hline 8 & no complaints & - & - & $=$ \\
\hline
\end{tabular}

Another observation from this study is that the children who had very poor or no orientation of time, space, having a very messed up life, have become more oriented about time and space, develop coordination in various activities of self and that of the others. Though there was not much improvement in their learning skills, social behavior has improved, they have started smiling, greeting
Others, wanted to remain in a group rather than living alone. Before this intervention, teachers had to catch hold of the children for the classroom study, games, and food, but after these practices they became more responsible and started coming to the classroom to study, asking for doing exercises, meditation and games; the teachers did not have to go around looking for them. 
Also, some of them won prizes in various vocational competition programs in the town. At the beginning of the intervention, the investigator used to take $1 \mathrm{hr}$ and 45 minutes to make them learn yoga and meditation, but now the investigator can finish the same in 30 to 40 minutes only.

\section{Discussion}

In the present study, it has been observed that the YPV intervention has brought several noteworthy and significant changes in the qualitative and quantitative measures of the parameters in the life of mentally challenged children. There was a statistically significant improvement in the mild and moderately retarded children in their cognitive abilities viz.

Understanding, concentration, concept, understanding \& memory \& other learning skills. Continuing the practice of the YPV techniques helps to maintain, sustain and make further progress of their learning skills and social behavior, though not much significant change in the IQ as observed.

The gross motor skill was the same pre and postintervention but fine motor skills like drawing, vocational training in the form of craft learning were improved, and started writing with a pen/pencil [1517].

Also, in children with mental retardation combined with refractory cases of epilepsy, there was a significant reduction in the severity, frequency, duration of epilepsy which has led them to live a better quality of life, improving their cognitive abilities.

For example one child with cerebral palsy had absenteeism from the school for 6 months, and as these children have a short memory, when they join back the classes, the same repetition again is needed to brush up the previously learned things, which is one of the challenges these children have [18-21].

\section{Conclusion}

There was a noticeable improvement in concentration, understanding, social behavior, memory, concept formation following YPV intervention, along with this, the frequency, duration and severity of the epilepsy is reduced in the refractory subjects of epilepsy with mental retardation.

\section{What does the study add to the existing knowledge?}

The present pilot study has demonstrated that YPV, as an effective modality of complementary therapy in improving the social behaviour, cognitive abilities and IQ of the mentally challenged children, the sooner the intervention is undertaken for them the better is the quality of life for them in their mental, emotional, and physical health domains. It is recommended that further controlled trials with larger test groups may be undertaken to validate the findings for wider application and generalizability.

\section{Author's contribution}

Dr. Rajkumari Khatri: Manuscript preparation, Ms. Shilpa Bembalkar: Study design, concept, Dr. V S Nanduri: Manuscript preparation

\section{Acknowledgements}

-To the Dean, teachers and students of the Govt school of mentally challenged children, Indore.

-To Sri Ramana Trust, Thally-635118, Tamilnadu for permission to use copyright terms Yoga Prana Vidya () and YPV $®$

\section{Reference}

01. Narayan CL, John T. The Rights of Persons with Disabilities Act, 2016- Does it address the needs of the persons with mental illness and their families. Indian J Psychiatry. 2017;59(1)17-20. doi: 4103/psychiatry.IndianJPsychiatry_75_17 [Crossref]

02. Kishore M T, Udipi GA, Seshadri SP. Clinical practice guidelines for assessment and management of intellectual disability. Indian J Psychiatry. 2019;61, Suppl S2;194-210.

Available from: [Article] [Crossref]

03. World Health Orgaisation (WHO). ICD-10 Classification of Mental and Behavioural Disorders. AITBS Publishers \& distributorsDelhi. 2006I225-231.

[Crossref]

04. Khare, SD. Mental Retardation affects quality of life in families of disabled children and role of nursing practices- A review. (IJNR). 2015;1 (1) 100-109.

[Crossref] 
05. Peck HL, Kehle TJ, Bray MA, Theodore LA. Yoga as an Intervention for Children With Attention Problems. School Psychology Review. $2005 ; 34(3) 415-424$.

[Crossref]

06. Gurjeet S Birdee, Gloria Y Yeh, Peter M Wayne, Russell S Phillips, Roger B Davis, Paula Gardiner. Clinical Applications of Yoga for the Pediatric Population- A Systematic Review. Acad Pediatr. 2009;9(4)212-220.

[Crossref]

07. Lisa C, Kaley Isley, John Peterson, Colleen Fischer, Emily Peterson. Yoga as a complementary therapy for children \& adolescents (Review). Psychiatry (Edgemont). 2010;7(8)20-32.

[Crossref]

08. Patricia Cabral, Hilary B Meyer, Donna Amer. Effectiveness of Yoga therapy as a complementary treatment for major Psychiatric disorders-A Meta-analysis. Prim care companion CNS Discord. 2011;13(4)pcc10r01068.

[Crossref]

09. Maherra Desai, Munira Kapadiya, Rajesh Parikh. Yoga and Meditation in promoting mental health. Acta Scientific Neurology. 2019;2(9)416. [Crossref]

10. Chittaranjan Andrade, Rajiv Radhakrishnan. Prayer and healing- A medical and scientific perspective on randomized controlled trials. Indian J Psychiatry. 2009;51(4).

[Crossref]

11. Arndt Bussing, Andreas Michalsen, SatBirS Khalsa, Shirley Telles, Karen J Sherman. Review Article Effects of Yoga on Mental and Physical Health- A Short Summary of Reviews. EvidenceBased Complementary and Alternative Medicine. 2012;7.

DOI: $10.1155 / 2012 / 165410$ [Crossref]

12. Anita Verma, Sanjay Uddhav Shete, Ghanshyam Singh Thakur, Dattatraya deVarao Kulkarni, Ranjit Singh Bhogal. The Effect of Yoga Practices on Cognitive Development in Rural Residential School Children in India. National Journal of Laboratory Medicine. 2014 Sep;3(3)15-19. [Crossref]
13. Pisa Vishvanath, Tikhe Sham Ganpat, Balram pradhan, Manmath Manohar Gharote, Nagendra Hongasandra Ramarao. Mentally Retarded children -A Scope for yoga Rehabilitation module. CHRISMED Journal of Health \& Research. 2016;3(1)98-99.

[Crossref]

14. Uma K, Nagendra HR, Nagarathna R, Vaidehi S, Seethalakshmi $R$. The integrated approach of yoga- a therapeutic tool for mentally retarded children, a one-year controlled study. J Ment Defic Res. 1989;33(Pt 5)415-421.

[Crossref]

15. Soren Ventegodt, Niels Jorgen Andreson, Joav Merrick Holistic. medicine III- The Holistic process- Theory of Healing. The Scientific World Journal. 2003;3;1138-46.

[Crossref]

16. Panebianco M, Sridharan K, Ramaratnam S. Yoga for epilepsy. Cochrane Database of Systematic Reviews. 2017;10.

DOI: 10.1002/14651858.CD001524.pub3 [Crossref]

17. Eyerman J. Transcendental meditation and mental retardation. J Clin Psychiatry. $1981 ; 42(1) 35-6$.

[Crossref]

18. Hopkins J T, Hopkins L J. A study of yoga and concentration. Academic Therapy. 1979;14(3). [Crossref]

19. S Ramaratnam, Sridharan K. "Yoga for epilepsy". Cochrane Database of Systematic Reviews. 2000;341-345.

[Crossref]

20. Neravetla J, Nanduri VS. A study into successful treatment of some difficult Medical cases using Yoga Prana Vidya (YPV) Healing System as alternative medicine. International Journal of Scientific \& Engineering Research. 2019;10(7)882-887.

[Crossref]

21. Astin John, Harkness Elaine, Ernst Edzard. The efficacy of "Distant Healing"- a systematic review of randomized trials. Annals of internal medicine. 2000;132;903-10.

[Crossref] 